\title{
Numerical Investigation of Downhole Perforation Pressure for a Deepwater Well
}

\author{
Qiao Deng ${ }^{1}{ }^{\oplus}$, Hui Zhang ${ }^{1, *}$, Jun Li ${ }^{1}$, Xuejun Hou ${ }^{2}$ and Binxing Zhao ${ }^{3}$ \\ 1 College of Petroleum Engineering, China University of Petroleum-Beijing, 18 Fuxue Road, \\ Changping 102249, China; bridges0307@hotmail.com (Q.D.); lijuncup2018@163.com (J.L.) \\ 2 School of Petroleum Engineering, Chongqing University of Science \& Technology, 20 East Road, \\ University City, Shapingba District, Chongqing 401331, China; xuejunhou1973@163.com \\ 3 School of Optoelectronic Science and Engineering, University of Electronic Science and Technology of China, \\ Chengdu 610054, China; zhaobxing@uestc.edu.cn \\ * Correspondence: zhanghuicup2018@163.com; Tel.: +86-199-1988-1457
}

Received: 29 August 2019; Accepted: 4 October 2019; Published: 8 October 2019

check for updates

\begin{abstract}
During the production of deepwater wells, downhole perforation safety is one of the key technical problems. The perforation fluctuating pressure is an important factor in assessing the wellbore safety threat. Due to difficulty in describing the downhole perforation pressure by using the existing empirical correlations, a prediction model based on data fitting of a large number of numerical simulations has been proposed. Firstly, a numerical model is set up to obtain the dynamic data of downhole perforation, and the exponential attenuation model of perforation pressure in the wellbore is established. Secondly, a large number of numerical simulations have been carried out through orthogonal test design. The results reveal that the downhole perforation pressure is logarithmic to the total charge quantity, increases linearly to the wellbore initial pressure, shows an exponential relationship with downhole effective volume for perforation, and has a power relationship with the thickness of casing and cement as well as formation elastic modulus. Thirdly, the prediction of perforation peak pressure at different positions along the wellbore agrees well with the field measurement within a 10\% error. Finally, the results of this study have been applied in the field case, and an optimization scheme for deepwater downhole perforation safety has been put forward.
\end{abstract}

Keywords: deepwater well; perforation safety; peak pressure; numerical model; orthogonal test

\section{Introduction}

With the improvement of oil and gas resources exploitation technology, more and more offshore oil and gas resources have been exploited in recent years [1,2]. The exploitation of deepwater oil and gas resources has increased gradually, and the safety of downhole perforation is an important technical problem [3]. The shaped charge jet perforation has been widely used in deepwater completion operations, the purpose of which is to form a channel between reservoir and wellbore that can effectively transport oil and gas [4,5]. On the one hand, the energy released by the explosion of perforating charge is converted into the effective energy to penetrate casing. On the other hand, part of the energy will be released into the wellbore, resulting in the pulsation of perforation pressure in the wellbore. This is the beginning of the wellbore dynamic effect in the process of perforation, in which the pulsating pressure of perforation will produce strong impact loads on the downhole tools and affect the stability of the whole perforation system [6-8]. Predicting the magnitude of downhole perforation pressure is a critical step for the safety analysis of deepwater perforation.

Perforation testing refers to the process of connecting perforating gun, upper operating string, and packer into a cluster for downward entry. The downhole perforation system for the deepwater wells is 
shown in Figure 1, which shows that the wellbore is filled with fluid after the packer is set. With the increase of water depth, the perforation process of deepwater wells is more complex and difficult. This is bound to greatly increase the downhole perforation pressure and wellbore safety risk. The normal exploitation of oil and gas will be affected, and even some irreparable damage may be caused.

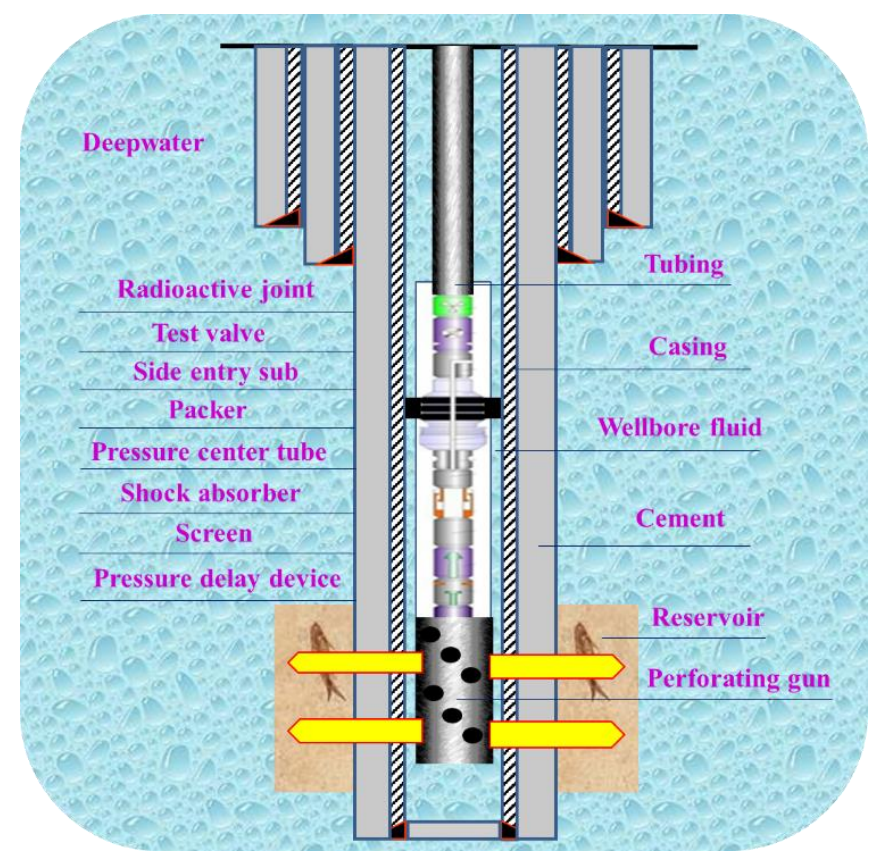

Figure 1. Downhole perforation system.

The fluctuating pressure of perforation mainly comes from the asymmetric dynamic loads, which are produced by the explosion of many perforating bullets arranged in a certain phase in the perforating gun. Progress has been made in this field in recent years. Lu et al. [9] proposed a perforation pressure equation based on reservoir conditions by using the superposition principle, with preliminary theoretical derivation and qualitative analysis. Zhao et al. $[10,11]$ qualitatively studied the characteristics of perforation pressure fluctuation in the process of composite perforation by combining theoretical research with experimental tests. Chen et al. [12] analyzed the dynamic load of downhole perforation by using theoretical empirical formula and simulation software. Sanders et al. [13] proposed that the pulsating pressure of downhole perforation would increase the risk of downhole equipment damage in deepwater well. Yang et al. [14] indirectly calculated the peak pressure of downhole perforation by calculating the energy of detonation gas based on the detonation theory. Zhou et al. [15] used the load test system to measure perforation pressure data downhole. Bale et al. [16] developed a commercial perforation software to simulate the dynamic downhole perforation pressure of deepwater wells. Li et al. [17] pointed out that the change and distribution of perforation impact pressure in the wellbore with time is not clear and needs further investigation. Liu et al. [18] set up a pressure field model of shaped charge to study the downhole perforation impact pressure. These studies have promoted the research progress of downhole perforation pressure. However, the functional relationships between downhole perforation pressure and different influencing factors are not clear. The distribution of perforation pressure along the wellbore is not clear. There is a lack of an accurate method to predict the magnitude of perforation pressure by considering multiple downhole influencing factors.

There are three main methods to study the dynamic pressure of downhole perforation, which are the empirical formula calculation, laboratory test, and numerical simulation [19]. However, due to the asymmetric load of perforating bullets and the complexity of the downhole dynamic environment, it is difficult to comprehensively describe the whole perforation process by relying solely on the existing empirical formulas. The data obtained by the laboratory test for perforation is limited. Therefore, the 
numerical simulation method of non-linear dynamics can be applied to describe the three-dimensional dynamic process of downhole perforation.

In this study, the parameters setting of the model materials and the state equations have been explored. By setting the fluid-structure coupling, the modeling method of multiple perforating bullets is formed. The complex perforating conditions are successfully simulated by LS-DYNA software on a large computer. The physical process of perforation with hundreds of perforating bullets has been innovatively simulated. Based on the simulated data, the functional relationships between perforation peak pressure and different influencing factors have been obtained. A prediction model to calculate the downhole perforating peak pressure has been proposed. The perforation peak pressure at different positions in the wellbore can be obtained.

\section{Empirical Formulas of Perforation Pressure}

At present, the calculation of downhole perforation pressure is mainly based on the empirical formulas of the explosive explosion. One of them is referring to the method of measuring explosive performance in an isolated container. It is assumed that the perforating charge is put in the sealed casing and the remaining space of which is filled with air. The empirical formula of explosive explosion pressure is used to calculate perforation pressure, as shown in [20]:

$$
P=\frac{f \omega}{V-\alpha \omega}
$$

where $P$ is the explosive pressure, $\mathrm{MPa} ; f$ is the explosive specific energy, $\mathrm{J} / \mathrm{kg}$; $\omega$ is the perforating charge quantity, $\mathrm{kg}$; $V$ is the effective volume of the casing, $\mathrm{L} ; \alpha=0.001 v, v$ is the Hexogen specific volume, $\mathrm{L} / \mathrm{kg}$.

By equating the perforating charge explosion with the underwater explosion test, the perforating pressure at different locations is calculated by [21]:

$$
P=K\left(\frac{\omega^{1 / 3}}{R}\right)^{\beta}
$$

where $K$ is the tested coefficient, 44.5 for spherical TNT explosive, dimensionless; $\omega$ is the explosive quality, $\mathrm{kg} ; R$ is the distance from the detonation center, $\mathrm{m} ; \beta$ is the attenuation coefficient, 1.5 for spherical TNT explosive, dimensionless.

Based on the detonation theory, the energy of detonation products is determined according to the detonation parameters of the perforating charge. The explosion pressure of perforation is obtained by [22]:

$$
P=1.558 \rho^{2} N \sqrt{M Q}
$$

where $\rho$ is the explosive density, $\mathrm{g} / \mathrm{cm}^{3} ; N$ is the molar number of the detonation gas products per unit mass of explosive, $\mathrm{mol} / \mathrm{g} ; M$ is the average molar mass of detonation gas components, $\mathrm{g} / \mathrm{mol} ; Q$ is the detonation heat, $\mathrm{KJ} / \mathrm{mol}$.

Assuming that a certain proportion of explosive energy will be converted into wellbore fluid internal energy, a certain increment of pressure can be produced in the wellbore. After perforation, the wellbore pressure is obtained as [23]:

$$
P=P_{0}+\varphi(\delta-1) \frac{n}{V} \frac{m}{M} Q
$$

where $P_{0}$ is the wellbore initial pressure, $\mathrm{MPa} ; \varphi$ is the explosive energy transfer rate, dimensionless; $\delta$ is the imaginary gas-liquid ratio in the wellbore, dimensionless; $n$ the number of perforating bullets; $m$ is the charge per hole, $\mathrm{g} ; M$ is the average molar mass of detonation gas components, $\mathrm{g} / \mathrm{mol} ; V$ is the wellbore effective volume, $\mathrm{m}^{3} ; Q$ is the detonation heat, $\mathrm{KJ} / \mathrm{mol}$. 
The idea of the above empirical formulas is to calculate the explosion pressure of perforation by the equivalent explosion of explosives. It is assumed that other calculation parameters remain constant: charge density is $1.80 \mathrm{~g} / \mathrm{cm}^{3}$; inner diameter of casing is $0.157 \mathrm{~m}$; casing length is $2.5 \mathrm{~m}$; inner diameter of tubing is $0.059 \mathrm{~m}$; tubing length is $1 \mathrm{~m}$; inner diameter of perforating gun is $0.105 \mathrm{~m}$; gun length is $1 \mathrm{~m}$; residual volume of charge is $0.83 \mathrm{~L} / \mathrm{kg}$; explosive specific energy is $1181861 \mathrm{~J} / \mathrm{kg}$; molecular mass of explosive is $222.12 \mathrm{~g} / \mathrm{mol}$; molar number of explosive per unit mass is 0.03377 ; detonation heat is $6205.23 \mathrm{KJ} / \mathrm{mol}$. The initial wellbore pressure is $10 \mathrm{MPa}$, with $30 \%$ of explosive energy converted into wellbore pressure during perforation. The total charge quantity of perforation is calculated as a variable by Equations (1)-(4), which is changed as $2 \mathrm{~kg}, 4 \mathrm{~kg}, 6 \mathrm{~kg}, 8 \mathrm{~kg}, 10 \mathrm{~kg}$. The calculation results are shown in Figure 2.

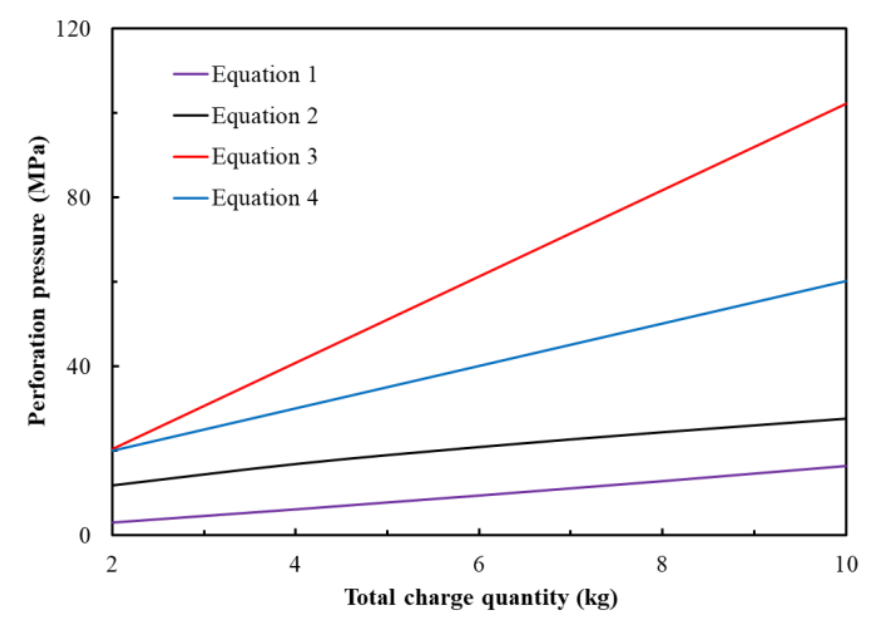

Figure 2. Calculation results from different empirical formulas.

Based on the above calculation results, it can be seen that the perforation pressure increases with the increase of the total charge quantity. The pressure values of perforation calculated Equations (1)-(4) are quite different. The actual downhole perforation conditions are complex, with many factors affecting the fluctuating pressure of perforation. The above empirical formulas cannot consider the factors comprehensively, especially for the influence of formation conditions. The calculation results of the above empirical formulas are inaccurate. It is important to account for the reservoir condition since it can act as an absorber or reflector (based on porosity, permeability, etc.) of shock waves that eventually affects the propagation and strength of shock waves within the wellbore $[24,25]$. Therefore, these theoretical empirical formulas can only be used as a preliminary reference for qualitative analysis of downhole perforation pressure. The above analysis shows that the charge of perforation, the effective space of the wellbore, the wellbore initial pressure, and so on are the important factors affecting the explosion pressure of perforation. Therefore, further research is needed to explore a more accurate calculation model for perforating pressure.

Due to high flexibility and ability, the technologies of numerical simulation have been widely applied for the study of complex non-linear problems in recent years. The simulation of perforation completion has undergone a process from simple to complex, and the perforation model has gradually developed from two-dimensional to three-dimensional. At present, the perforation simulation analysis has entered the stage of finite element simulation calculation with the further development of computer technologies. Some complex non-linear problems with high calculation accuracy have been solved with the premise of adapting to various complex mathematical models. The numerical simulation has many advantages and has become an effective means of piercing engineering analysis, in which the whole dynamic process can be presented by numerical simulation $[26,27]$. 


\section{Modeling and Meshing}

The whole process of perforation includes charge explosion, jet formation, casing penetration, and fluid-solid coupling. The sequential explosion of perforating bullets has an extremely complex coupling superposition effect with increasing shock loads in the wellbore. At present, the finite element software of LS-DYNA or AUTODYNA has been widely used to simulate the whole dynamic process. Lee [28] simulated the process of jet formation and penetration into the casing wall based on the 2D Euler coding, the foundation of perforation numerical simulation was laid. Han et al. [29] studied the process of explosive explosion forming jet and penetrating casing wall during perforation by numerical simulation. Kang et al. [30] used the software of LS-DYNA to study the dynamic response of the perforating gun, and few numbers of perforating bullets were simulated in three-dimensional. Yang [31] simulated a single perforating bullet of the horizontal well perforation by the software of LS-DYNA, and the state equations and model parameters during perforation were explored. Li [32] simulated the fluctuation of perforation pressure by the software of AUTODYN using spherical explosive instead of perforating bullets. Yan et al. [33] studied the process of perforation to cement damage by the software of LS-DYNA, and the ALE (Arbitrary Lagrange-Euler) algorithm was used to describe the fluid-structure coupling phenomenon in the perforation process. The above researches have laid the foundation for modern perforation completion simulation and promoted its rapid development. The selection of state equations, the setting of model parameters, and the fluid-structure coupling phenomenon in the perforation process have been preliminarily studied. However, previous work often focused on a single or a few numbers of perforation bullets due to the complexity of perforation modeling and meshing with huge workloads. Without considering the influence of multiple factors on downhole perforation pressure, the simulation cannot reflect the actual working conditions of perforation.

In this section, the perforation model, with hundreds of perforating bullets, has been innovatively established. Several trial calculations have been carried out by exploring the parameters of the model materials and state equation and setting the fluid-solid coupling interface. The numerical simulations have been carried out smoothly.

\subsection{Physical Model}

A number of perforating bullets are distributed in the gun at a certain phase. The downhole perforation system of deepwater wells has many components, as shown in Figure 1. The physical model needs to be simplified for the convenience of simulation calculation. Make the following assumptions: Firstly, the cement or reservoir is assumed as isotropic materials by ignoring their heterogeneity; Secondly, all the downhole components in the perforation string system are regarded as isotropic tubing string materials. Through the above assumptions, a 3D physical model can be established by simplification, as shown in Figure 3. The perforating gun, tubing string, and casing are involved in the model with 300 perforating bullets with phase $45^{\circ}, 63 \mathrm{~g}$ charge per hole. The air fills inside the remaining space of the gun. The wellbore fluid fills the annulus space of tubing and casing with the initial pressure of $15 \mathrm{MPa}$. The packer restrains the upper end of the string radially, and the circumference of the string is restrained by the casing with reservoir surrounding. 


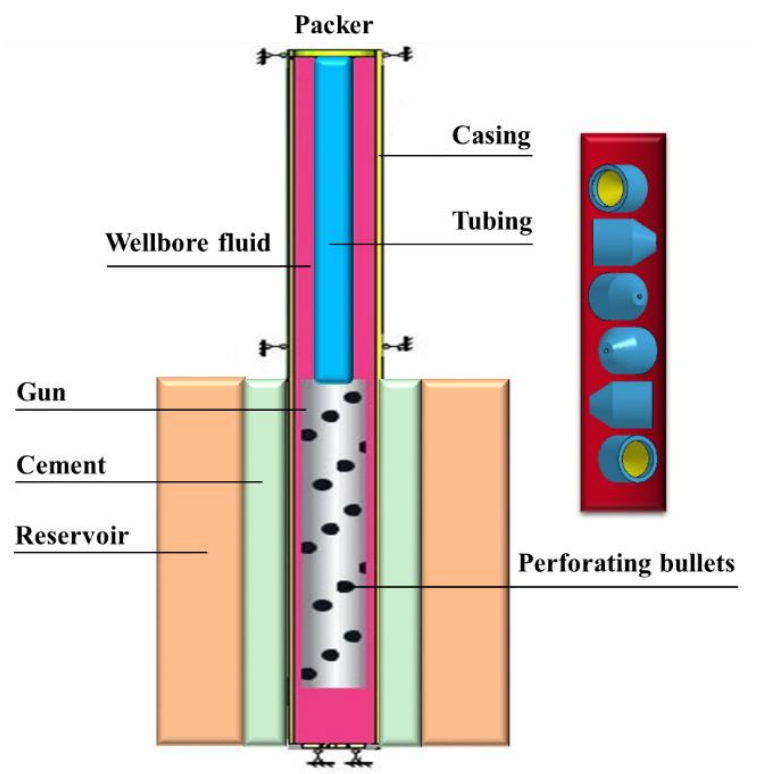

Figure 3. 3D physical model.

\subsection{Model Meshing}

The physical process of perforation includes complex fluid-structure interaction with a high strain rate, which is commonly solved by the BEM (boundary element method) and FEM (finite element method). The BEM is suitable for solving linear homogeneous problems, while FEM is suitable for solving nonlinear problems with complex boundaries [34,35]. Therefore, the finite element method can be used to simulate perforation. In LS-DYNA, there are mainly ALE (Arbitrary Lagrange-Euler) algorithm and SPH (Smoothed Particle Hydrodynamics) algorithm for fluid-structure interaction calculation. The mesh deformation caused by meshless can be avoided for the SPH algorithm [36]. However, the ALE algorithm is more stable under perforation conditions, accurately describing the deformation response of perforated string, cement, and reservoir without mesh non-convergence. The ALE algorithm can accurately simulate the formation and penetration of a shaped charge jet with a high strain rate and large deformation, which can be used in RDX (Royal Demolition Explosive) explosives, air, and fluid. The spatial position of the ALE grid remains unchanged with the material flows among the grids. The Lagrange algorithm is used in the downhole string. The Lagrange algorithm can be firstly executed by the ALE algorithm at each time step [37].

Since the model meshing is complex, the grid is built on the cylindrical boundary to make the whole area transition into a cuboid structure. The remaining $3 / 4$ models can be obtained by rotating the replication command. The fluid area model of the perforating bullet and the torsion model are connected by twisting the air area model between the cylindrical segments, in which different perforating bullets are located. The twisting model is connected by replicating rotation. The fluid area model of several perforating bullets can be obtained. Through the above methods, the geometric parameters of the liner, charge, the height of the upper end face of the cuboid, and the number of corresponding meshes can be adjusted. Different sizes of the perforating bullets can be quickly established by changing the parameters. Multiple perforating bullets can be obtained by simple replication with the distance that can be quickly adjusted. Figure 4a shows the vertical section of the mesh model, and the vertical section of the mesh model of the perforating bullet is shown in Figure $4 \mathrm{~b}$. 


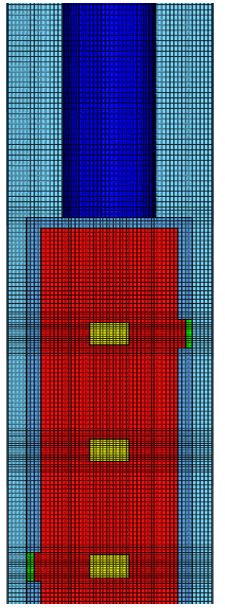

(a)

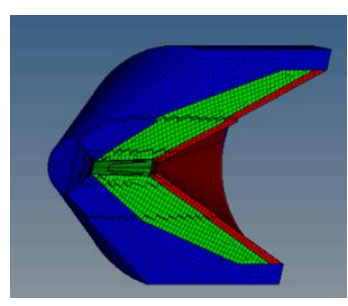

(b)

Figure 4. Meshing: (a) vertical section of mesh model; (b) mesh model of perforating bullet.

\subsection{Material Model and State Equation}

The selection of material parameters and the related equation of state have been briefly introduced in the section. The state equation of EOS_JWL (Jones-Wilkins-Lee) is adopted for RDX explosive, and the expression is shown in [38]:

$$
P=A\left(1-\frac{\omega}{R 1 V}\right) e^{-R 1 V}+B\left(1-\frac{\omega}{R 2 V}\right) e^{-R 2 V}+\frac{\omega E}{V}
$$

where $p$ is the pressure of detonation product, $\mathrm{MPa} ; V=\frac{1}{\rho}$ is the specific volume, $\mathrm{cm}^{3} / \mathrm{g} ; A, B, \omega, R 1, R 2$ are material constants; $E$ is the explosive internal energy of unit volume, $\mathrm{J} / \mathrm{m}^{3}$. The parameters' values are listed in Table 1.

Table 1. Parameters' values of RDX (Royal Demolition Explosive).

\begin{tabular}{cccccccc}
\hline$\rho\left(\mathrm{g} / \mathrm{cm}^{3}\right)$ & $\boldsymbol{D}(\mathrm{cm} / \mu \mathrm{s})$ & $\boldsymbol{A}(\mathrm{GPa})$ & $\boldsymbol{B}(\mathrm{GPa})$ & $\boldsymbol{R}_{\mathbf{1}}$ & $\boldsymbol{R}_{\mathbf{2}}$ & $\omega$ & $E\left(\mathrm{~J} / \mathrm{m}^{\mathbf{3}}\right)$ \\
\hline 1.78 & 0.65 & 3.71 & 0.074 & 4.15 & 0.95 & 0.3 & $9 \times 10^{9}$ \\
\hline
\end{tabular}

The MAT_NULL material model and state equation of EOS_GRUNEISEN are used for describing the wellbore fluid (water) dynamic response. The equation is shown in [39]:

$$
P=\frac{\rho_{0} C^{2} \mu\left[1+\left(1-\frac{\gamma_{0}}{2}\right) \mu-\frac{a_{1}}{2} \mu^{2}\right]}{\left[1-\left(S_{1}-1\right) \mu-S_{2}^{2} \frac{\mu^{2}}{\mu^{2}+1}-S_{3} \frac{\mu^{3}}{(\mu+1)^{2}}\right]}+\left(\gamma_{0}+a_{1} \mu\right) E
$$

where $C$ is the sound velocity in water, $\mathrm{cm} / \mu \mathrm{s} ; S 1, S 2, S 3$ are the constant coefficients, dimensionless; $\gamma_{0}$ is the Gruneisen constant, dimensionless; $\mu=\frac{\rho}{\rho_{0}}-1$ is the water compressibility, dimensionless; $a_{1}$ is the first-order volume correction of $\gamma_{0}, \mu$, dimensionless. The main parameter values are shown in Table 2.

Table 2. Water parameters of the Gruneisen state equation.

\begin{tabular}{ccccccccc}
\hline$C(\mathrm{~cm} / \mu \mathrm{s})$ & $S_{1}$ & $S_{2}$ & $S_{3}$ & $\gamma_{0}$ & $a_{1}$ & $A$ & $E_{0}$ & $V_{0}$ \\
\hline 0.165 & 1.92 & -0.0096 & 0 & 0.35 & 0.47 & 0 & 0 & 0.9925 \\
\hline
\end{tabular}


The EOS of material air is shown as [40]:

$$
P=\left(C_{0}+C_{1} \mu+C_{2} \mu^{2}+C_{3} \mu^{3}\right)+\left(C_{4}+C_{5} \mu+C_{6} \mu^{2}\right) E
$$

where $C_{0}, C_{1}, C_{2}, C_{3}, C_{4}, C_{5}, C_{6}$ are the EOS parameters, dimensionless. The values of the parameters are shown in Table 3.

Table 3. Air parameters.

\begin{tabular}{cccccccc}
\hline$\rho\left(\mathrm{g} / \mathrm{cm}^{3}\right)$ & $C_{0}$ & $C_{1}$ & $C_{2}$ & $C_{3}$ & $C_{4}$ & $C_{5}$ & $C_{6}$ \\
\hline 0.001225 & 0 & 0 & 0 & 0 & 0.4 & 0.4 & 0 \\
\hline
\end{tabular}

The Cowper-Symonds model is adopted for the shell and perforated string (gun, tubing, casing), as shown in [41]:

$$
\sigma_{y}=\left[1+\left(\frac{\varepsilon}{Q}\right)^{\frac{1}{P}}\right]\left(\sigma_{0}+\beta E_{p} \varepsilon_{P}^{e f f}\right)
$$

where $\varepsilon$ is the strain rate of materials, dimensionless; $Q$ and $P$ are the strain rate parameters, dimensionless; $\sigma_{0}$ is the initial value of yield stress, $\mathrm{MPa} ; E_{P}=\frac{E_{\tan } E}{E-E_{\tan }}$ is the plastic hardening modulus of materials, GPa; $E_{\tan }$ is the tangent modulus of materials, GPa; $E$ is the young modulus of materials, $\mathrm{GPa} ; \varepsilon_{P}^{e f f}$ is the effective plastic strain of materials, dimensionless. According to the API (American Petroleum Institute) standard, the material parameters of the perforated string are shown in Table 4 [42].

Table 4. Parameters of perforated string.

\begin{tabular}{cccccccc}
\hline Parameters & $\begin{array}{c}\text { Steel } \\
\text { Grade } \\
-\end{array}$ & $\begin{array}{c}\text { Length } \\
\mathbf{( m )}\end{array}$ & $\begin{array}{c}\text { Density } \\
\mathbf{( k g / \mathbf { m } ^ { 3 } )}\end{array}$ & $\begin{array}{c}\text { Size } \\
\mathbf{( m m )}\end{array}$ & $\begin{array}{c}\text { Yield } \\
\text { Stress } \\
\mathbf{( M P a )}\end{array}$ & $\begin{array}{c}\text { Elastic } \\
\text { Modulus } \\
\mathbf{( G P a )}\end{array}$ & $\begin{array}{c}\text { Poisson's } \\
\text { Ratio }\end{array}$ \\
\hline Tubing & $\mathrm{N} 80$ & 20 & 7800 & $93 / 62$ & 536 & 206 & 0.3 \\
Casing & $\mathrm{N} 80$ & 35 & 7800 & $245 / 221$ & 460 & 206 & 0.25 \\
Gun & N80 & 9 & - & $178 / 153$ & 550 & 206 & 0.3 \\
\hline
\end{tabular}

The cement and reservoir can be described by the material model of Holmquist-Johnson-Cook model [38]:

$$
\sigma=f_{c}\left[Q_{1}\left(1-Q_{2}\right)+Q_{3} P^{* N}\right]\left[1+Q_{4} \ln \left(\varepsilon^{*}\right)\right]
$$

where $f_{c}$ is the uniaxial compression strength, MPa; $P^{* N}$ is the normalized pressure value, dimensionless; $\varepsilon^{*}$ is the normalized strain rate, dimensionless; $Q_{1}, Q_{2}, Q_{3}$ are the constants of the material, dimensionless; $Q_{4}$ is the damage value, dimensionless. In order to reduce the amount of calculation, the cement and reservoir model is only established near the perforation section. The modeling parameters are shown in Table 5.

Table 5. Cement and reservoir parameters.

\begin{tabular}{ccccccc}
\hline Parameters & $\begin{array}{c}\text { Density } \\
\left(\mathbf{k g} / \mathbf{m}^{\mathbf{3}}\right.\end{array}$ & $\begin{array}{c}\text { Length } \\
\mathbf{( m )}\end{array}$ & $\begin{array}{c}\text { Thickness } \\
\mathbf{( m )}\end{array}$ & $\begin{array}{c}\text { Inner Diameter } \\
(\mathbf{m m})\end{array}$ & $\begin{array}{c}\text { Elastic Modulus } \\
(\mathbf{G P a})\end{array}$ & $\begin{array}{c}\text { Poisson's Ratio } \\
-\end{array}$ \\
\hline Cement & 2560 & 20 & 0.03 & 245 & 206 & 0.3 \\
Reservoir & 2210 & 20 & 3 & 545 & 1.27 & 0.35 \\
\hline
\end{tabular}

The numerical model is input into the LS-DYNA program in the form of a $\mathrm{K}$ file for calculation. The parameters of numerical simulation are defined by keywords. * INCLUDE and * INCLUDE TRANSFORM: importing the grid model information; * INITIAL_DETONATION: defining the initiation point and time of explosives; * ALE_MULTI-MATERIAL_GROUP: making the material flows with each other in the fluid domain grid; *CONSTRAINED_LAGRANGE_IN_SOLID: realizing the 
fluid-solid coupling; * SECTION_SOLID and * SECTION_SOLID_ALE: setting the grid cell algorithms; * CONTROL_TERMINATION and ${ }^{*}$ CONTROL_TIMESTEP: controlling the simulation time and the output step of the model calculation [37].

\section{Numerical Analysis}

In this section, numerical simulation has been carried out on a large computer based on the above modeling and calculation methods. The simulation data can be extracted through post-processing. The total explosion time during perforation of 0-5000 $\mu$ s has been simulated.

\subsection{Simulation Results}

The perforation pressure in the wellbore distribution from $800 \mu \mathrm{s}$ to $1400 \mu \mathrm{s}$ with an interval of 100 microseconds can be obtained, as shown in Figure 5. When the perforator has not been detonated, there is no fluctuation of the pressure in the wellbore. When the shock wave is formed by the explosion of perforating bullets, the perforation pressure in the wellbore increases sharply upward along the wellbore. When the shock wave reaches the position of the packer at the top of the wellbore, it reaches the peak value, which is caused by the reflection of the packer. The reflected shock wave gradually propagates downward along the wellbore, showing a trend of attenuation. The wellbore pressure-time curve can be drawn by extracting the simulated data, as shown in Figure 6.

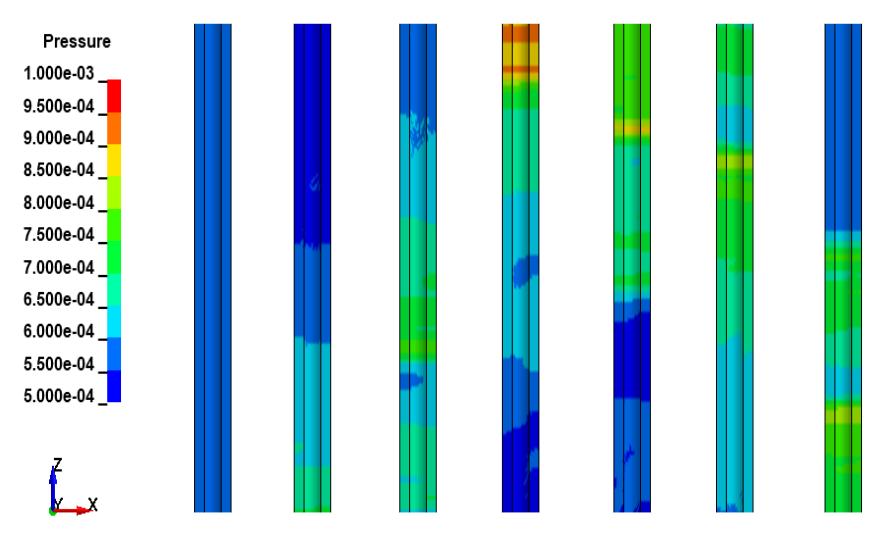

Figure 5. Perforation pressure distribution in the wellbore (unit: $10^{11} \mathrm{~Pa}$ ).

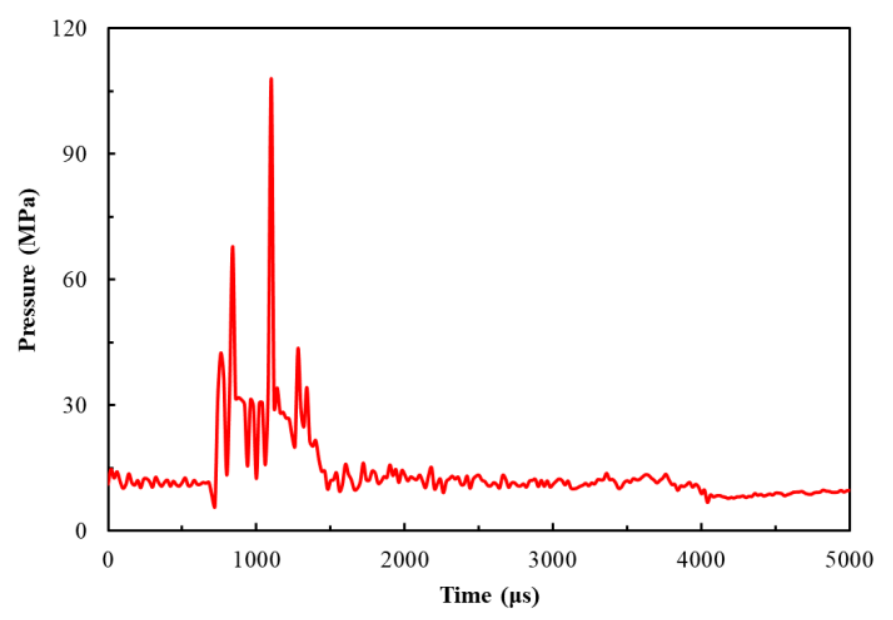

Figure 6. Simulated perforation pressure-time curve.

It can be seen from the simulated perforation pressure-time curve that the wellbore pressure reaches peak instantaneously with the detonation of the perforating bullets. Then, the oscillation occurs when shock waves are reflected back and forth in the wellbore. The attenuation occurs with propagation in the wellbore fluid. Finally, the pressure value tends to be stable after perforation. 
The changing trend is similar to the field measured data curve, as shown in Section 5. It can be seen from Figure 6 that the peak pressure of deepwater perforation is as high as $110 \mathrm{MPa}$, which is a very important index for downhole wellbore safety. The high peak perforation pressure will cause the direct damage of downhole tools, such as the fracture of perforated string, the failure of the packer, etc. The peak value of perforation pressure can be used as the test index of the downhole safety for deepwater wells $[43,44]$. Before the shock wave reaches the packer, the contour of annulus pressure is captured along the different positions of the wellbore from bottom to top, as shown in Figure 7.

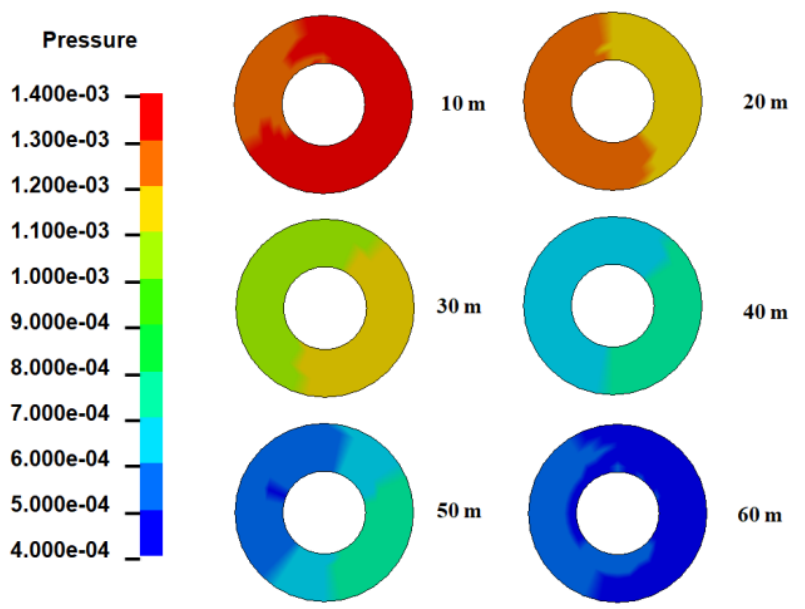

Figure 7. Perforation pressure distribution at different positions of the wellbore (unit: $10^{11} \mathrm{~Pa}$ ).

The position of perforating gun is regarded as the starting position of perforating explosive load. From Figure 7, it can be seen that the farther away from the source of the explosion, the lower the perforating pressure is. It means that the propagation of perforating pressure in wellbore fluid shows an attenuation trend. The peak perforation pressure at different positions in the wellbore can be extracted [45-49]. By using the extremum method, the simulated data can be dimensionless. The change trend curve of peak perforation pressure at different wellbore positions has been obtained, as shown in Figure 8.

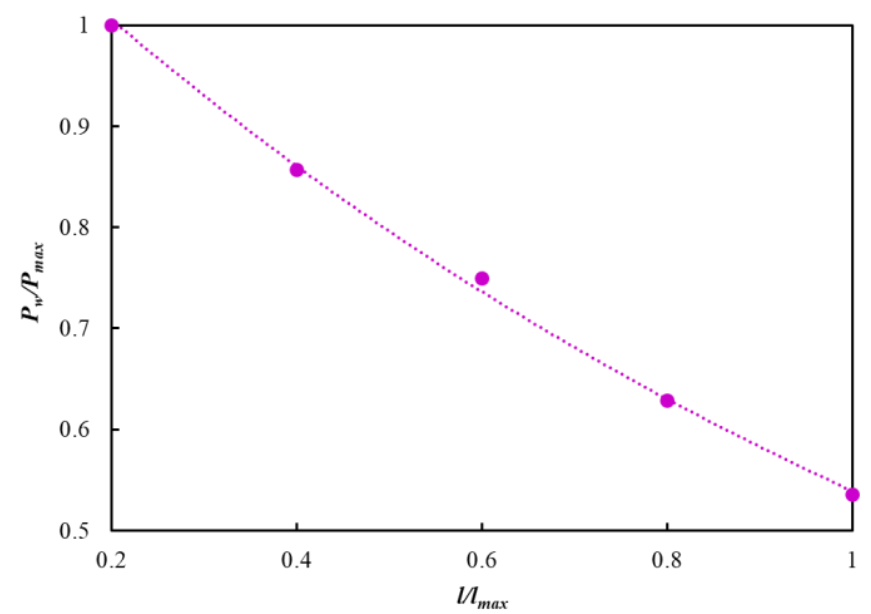

Figure 8. Perforation peak pressure at different positions of the wellbore. The abscissa $l / l_{\max }$ is the ratio of the distance along the wellbore from the source of the explosion and the distance from the packer to the source of the explosion. The ordinate $P w / P \max$ is the ratio of the peak pressure of perforation and the maximum peak pressure of perforation.

The ultra-high pressure detonation products formed by perforation bullets rapidly expand in wellbore fluid in the form of gas. Since the pressure of the detonation products is far greater than the 
static pressure of surrounding wellbore fluid, the shock waves and perforation pressure pulsation have been formed in the wellbore. There will be a decaying trend with the propagation of shock waves in the wellbore fluid. The physical process is very similar to the underwater explosion. The mathematical model of the underwater pressure attenuation is usually obtained by fitting the experimental data. Cole [50] first proposed the theory to describe the pressure attenuation of underwater explosion; it is considered that the propagation attenuation law of underwater explosion accords with exponential attenuation. Through the above analysis, the attenuation coefficient model of the downhole perforation pressure in the wellbore is proposed by the undetermined coefficient method:

$$
P w=K \times P s \times e^{\beta k}
$$

where $P w$ is the peak pressure of perforation at different positions of the wellbore, MPa; $P S$ is the initial pressure of the explosive source of perforation bullets, $\mathrm{MPa}$; $K$ is the undetermined coefficient, dimensionless; $\beta$ is the attenuation index, dimensionless; $k=l / l_{\max }$ is the ratio of the distance along the wellbore from the source of the explosion and the distance from the packer to the source of the explosion, dimensionless.

Based on the numerical simulation data in Figure 8, the model of the undetermined coefficient in the equation can be solved, $K=1.18$ and $\beta=-0.37$. In order to obtain the pressure of the source of the explosion of perforating bullets, a large number of numerical simulation analysis is carried out for different factors based on the orthogonal test.

\subsection{Orthogonal Test}

The orthogonal test is a scientific, effective, and simple method to study the influence of multiple factors, which is applicable to a certain index affected by these factors, with each factor taking more than one value. As we know, there are many factors affecting the pulse pressure of perforation, such as perforation-related parameters, pressure in the initial wellbore fluid, wellbore size, the thickness of casing and cement sheath penetrated, reservoir conditions, and so on. In this study, in order to obtain the variation law of downhole perforation pressure under different perforation conditions, the orthogonal test method has been used to carry out a series of numerical simulation calculations on a large computer for the influence of different factors on perforation pressure. Five correlative factors have been considered: total charge quantity, wellbore initial pressure, downhole effective volume for perforation, the thickness of casing and cement, formation elastic modulus. The designed orthogonal test table is shown in Table 6.

Table 6. Orthogonal test level table.

\begin{tabular}{cccccc}
\hline $\begin{array}{c}\text { Orthogonal } \\
\text { Test Level }\end{array}$ & $\begin{array}{c}\text { Total Charge } \\
\text { Quantity (kg) }\end{array}$ & $\begin{array}{c}\text { Wellbore } \\
\text { Initial } \\
\text { Pressure (MPa) }\end{array}$ & $\begin{array}{c}\text { Downhole } \\
\text { Perforation } \\
\text { Effective } \\
\left.\text { Volume } \mathbf{( m}^{\mathbf{3}}\right)\end{array}$ & $\begin{array}{c}\text { Thickness of } \\
\text { Casing and } \\
\text { Cement (m) }\end{array}$ & $\begin{array}{c}\text { Formation } \\
\text { Elastic } \\
\text { Modulus } \\
\mathbf{( M P a )}\end{array}$ \\
\hline Level 1 & 4 & 15 & 1.5 & 0.03 & 5 \\
Level 2 & 8 & 50 & 2 & 0.05 & 10 \\
Level 3 & 12 & 85 & 2.5 & 0.07 & 15 \\
Level 4 & 16 & 120 & 3 & 0.09 & 20 \\
\hline
\end{tabular}

The perforating peak pressure is the index affected by the factors; the results of orthogonal numerical simulation tests can be obtained in Table 7. Through range analysis, the order of importance of each factor to test index can be judged. The range can be calculated by the formula, as shown in [28]:

$$
R_{i}=\left\{\operatorname{Max}\left(K_{i}\right)-\operatorname{Max}\left(K_{i}\right)\right\} / n
$$


where $R_{i}$ is the range formula of the $i$ th column, dimensionless; $K_{i j}$ is the sum of the test indices corresponding to the $i$ th column (factor) and $j$ th level (value), dimensionless; $\bar{K}_{i j}$ is the average value of the test indices corresponding to the $i$ th column (factor) and $j$ th level (value), which can be used to obtain the optimum combination of factors to make the test index, dimensionless.

Table 7. Results of orthogonal tests.

\begin{tabular}{ccccccc}
\hline $\begin{array}{c}\text { Sequence } \\
\text { Number } \\
(-)\end{array}$ & $\begin{array}{c}\text { Total } \\
\text { Charge } \\
\mathbf{( k g )}\end{array}$ & $\begin{array}{c}\text { Wellbore } \\
\text { Initial } \\
\text { Pressure } \\
\mathbf{( M P a )}\end{array}$ & $\begin{array}{c}\text { Downhole } \\
\text { Effective } \\
\text { Volume } \\
\mathbf{( m}^{\mathbf{3}} \mathbf{)}\end{array}$ & $\begin{array}{c}\text { Thickness } \\
\text { of Casing } \\
\text { and Cement } \\
(\mathbf{m})\end{array}$ & $\begin{array}{c}\text { Formation } \\
\text { Elastic } \\
\text { Modulus } \\
\mathbf{( M P a )}\end{array}$ & $\begin{array}{c}\text { Peak Value of } \\
\text { Perforating } \\
\text { Pressure } \\
\mathbf{( M P a )}\end{array}$ \\
\hline 1 & 4 & 15 & 3 & 0.09 & 15 & 52.6 \\
2 & 4 & 50 & 2.5 & 0.07 & 20 & 89.88 \\
3 & 4 & 85 & 2 & 0.05 & 10 & 149.22 \\
4 & 4 & 120 & 1.5 & 0.03 & 5 & 206.2 \\
5 & 8 & 15 & 2.5 & 0.05 & 5 & 85.33 \\
6 & 8 & 50 & 3 & 0.03 & 10 & 148.55 \\
7 & 8 & 85 & 1.5 & 0.09 & 20 & 160.75 \\
8 & 8 & 120 & 2 & 0.07 & 15 & 208 \\
9 & 12 & 15 & 2 & 0.03 & 20 & 96.22 \\
10 & 12 & 50 & 1.5 & 0.05 & 15 & 140.74 \\
11 & 12 & 85 & 3 & 0.07 & 5 & 189.87 \\
12 & 12 & 120 & 2.5 & 0.09 & 10 & 215.17 \\
13 & 16 & 15 & 1.5 & 0.07 & 10 & 145.52 \\
14 & 16 & 50 & 2 & 0.09 & 5 & 195.68 \\
15 & 16 & 85 & 2.5 & 0.03 & 15 & 248.9 \\
16 & 16 & 120 & 3 & 0.05 & 20 & 276.65 \\
\hline
\end{tabular}

Through range analysis, the order of importance of each factor to the perforating peak pressure can be obtained. The larger the range value, the greater the influence of the factor on the peak perforation pressure is. The range value of the total charge quantity, wellbore initial pressure, downhole effective volume for perforation, the thickness of casing and cement, formation elastic modulus is $90.3,106.52$, $24.27,29.1,19.79$, respectively. Therefore, the order of influence of each factor on the peak value of perforation pressure is as follows: wellbore initial pressure $>$ total charge quantity $>$ thickness of casing and cement $>$ downhole effective volume for perforation $>$ formation elastic modulus.

\subsection{Analysis of Influence Factors}

In order to study the correlation between influence factors and peak perforation pressure, the dimensionless analysis is adopted for the simulated data. Five dimensionless normalized forms of the factors of the total charge quantity, wellbore initial pressure, downhole effective volume for perforation, the thickness of casing and cement, formation elastic modulus are represented by $X_{1}, X_{2}, X_{3}, X_{4}, X_{5}$, respectively. The dimensionless normalized form of peak perforation pressure can be represented by $Y$. The downhole wellbore perforation peak pressure function can be expressed in the dimensionless form:

$$
Y=f\left(X_{1}, X_{2}, X_{3}, X_{4}, X_{5}\right)
$$

where $X_{1}=M_{0} / M_{\max }, X_{2}=P_{0} / P_{0 \max }, X_{3}=V_{0} / V_{\max }, X_{4}=L_{0} / L_{\max }, X_{5}=G_{0} / G_{\max }$ are the ratios of the total charge quantity, wellbore initial pressure, downhole effective volume for perforation, the thickness of casing and cement, formation elastic modulus to the maximum value of that, respectively, dimensionless.

Based on the dimensionless simulation data, taking $X_{1}$ as abscissa and $Y$ as a longitudinal coordinate, the trend curve and the influence law can be obtained, as shown in Figure 9. 


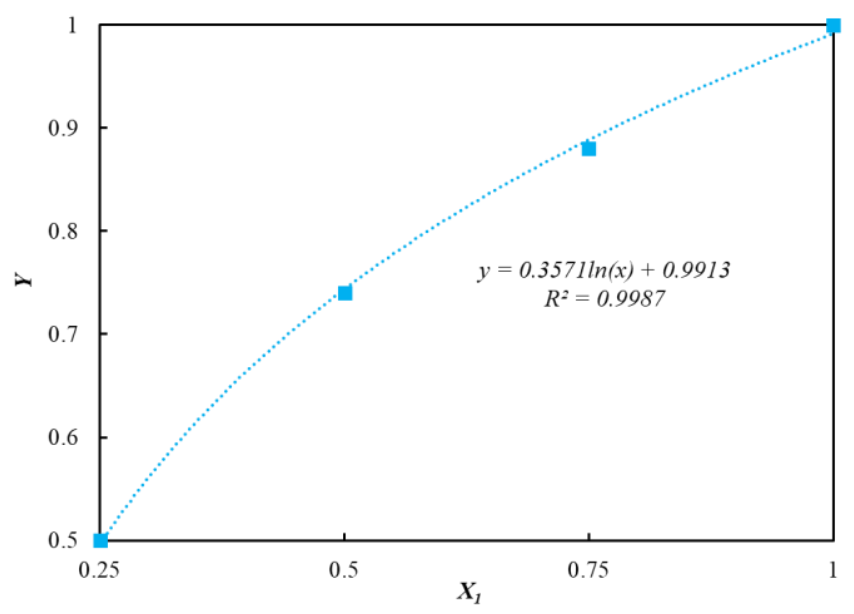

Figure 9. The influence of total charge quantity on downhole perforation peak pressure.

Figure 9 indicates that the peak value of perforation pressure and the total charge quantity show a logarithm function. The perforating peak pressure increases with the total charge quantity increasing. The reason is that the fluctuating pressure of downhole perforation mainly comes from the explosion source of perforated bullets with the shaped charge. The larger the single charge and the more the number of perforation bullets are, the more the total charge quantity is, the higher the peak pressure of perforation pulsation is.

Similarly, in order to investigate the effects of wellbore initial pressure on the pulsating pressure of perforation, the relationship between the wellbore initial pressure and the peak value of downhole perforation can be obtained in Figure 10.

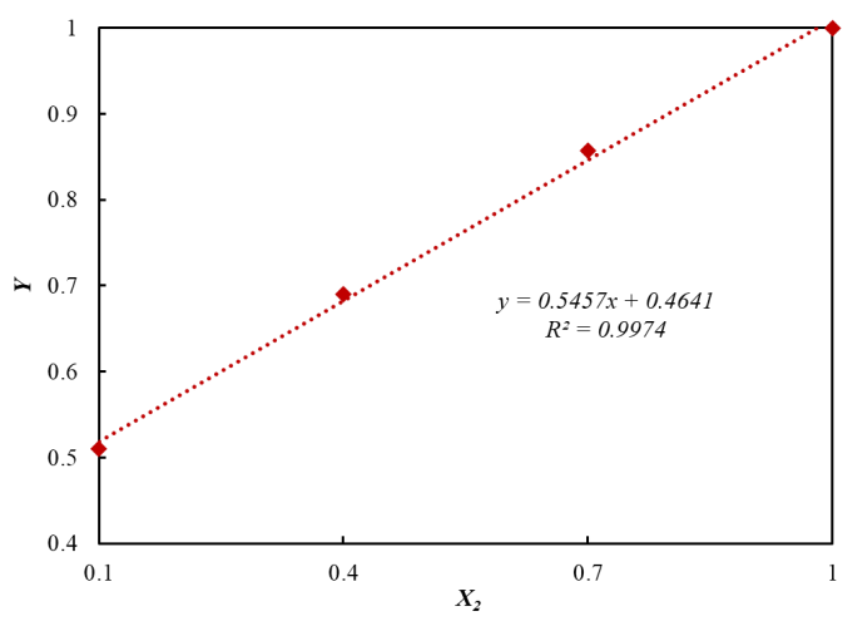

Figure 10. The influence of wellbore initial pressure on downhole perforation peak pressure.

As shown in Figure 10, the peak perforation pressure increases linearly with the increase of wellbore initial pressure. The reason is that the initial wellbore pressure provides the basis for the pulsating pressure of perforation. When the explosive energy produced by the explosion of the perforation bullets is released into the wellbore, the larger the wellbore initial pressure is, the higher the perforating explosion pressure is.

Figure 11 illustrates the relationship between the downhole perforation effective volume and the peak value of perforation. It can be seen that the peak value of perforation and the downhole perforation effective volume shows an exponential function. The peak value of perforation gradually becomes smaller with the increase of the downhole perforation effective volume. This is because as the packer is seated, the downhole wellbore is in a closed space. With the increase of downhole perforation 
effective volume, the energy generated by the perforation explosion has more space to release. Less energy can be converted into the perforating pulsating pressure.

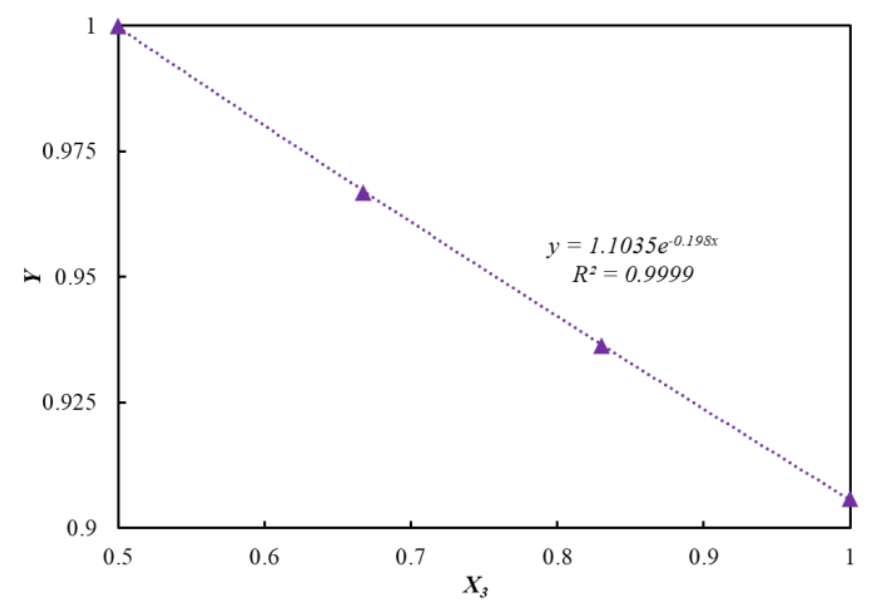

Figure 11. The influence of downhole perforation effective volume on perforation peak pressure.

The relationship between the thickness of casing and cement and the peak value of downhole perforating pressure can be drawn, as shown in Figure 12. It can be seen that the peak value of downhole perforating pressure and the thickness of casing and cement show a power relation function. The peak value of downhole perforating pressure gradually becomes smaller with the increase of the thickness of casing and cement. The reason is that with the increase of energy used to perforate casing and cement, the explosive energy released in wellbore decreases correspondingly. The pulsating pressure of perforation decreases accordingly.

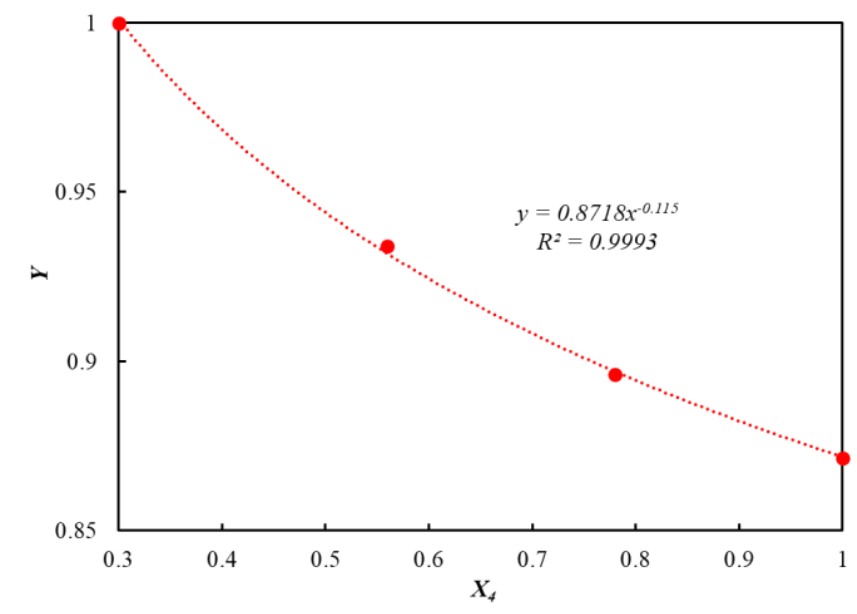

Figure 12. The influence of the thickness of casing and cement on downhole perforation peak pressure.

Figure 13 illustrates the relationship between the formation elastic modulus and the peak value of perforation pressure. It can be seen that the peak value of perforation pressure and the formation elastic modulus show a power function. The peak value of perforation pressure gradually becomes smaller with the increase of the formation elastic modulus. The reason is that the greater the formation elastic modulus is, the stronger the ability to resist elastic deformation is. More energy is required for perforation to penetrate the formation. Less energy will be released in the wellbore with the smaller perforating pressure. 


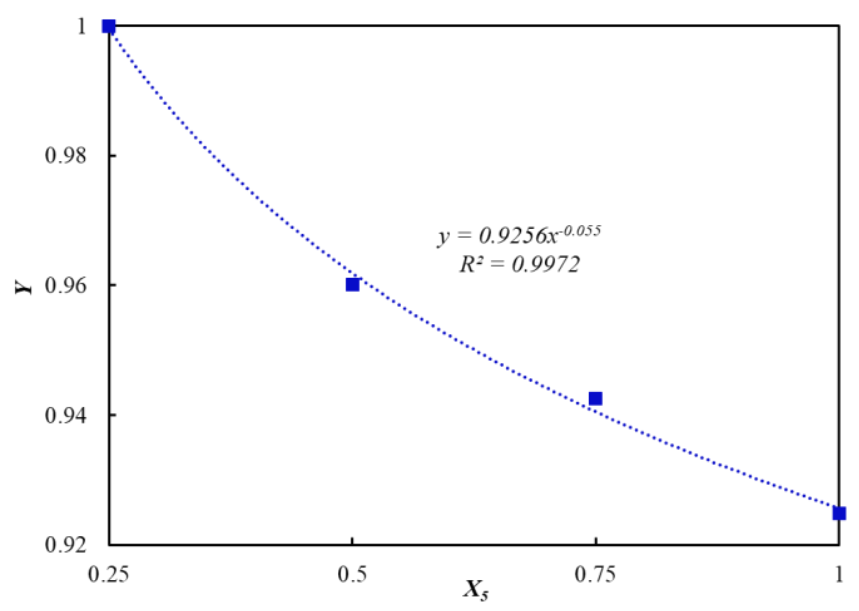

Figure 13. The influence of formation elastic modulus on downhole perforation peak pressure.

Based on the above analysis, the influence laws of the factors on the downhole perforation peak pressure have been obtained. In order to obtain a prediction model that can be used to calculate the peak pressure of perforation pulsation accurately in engineering, it can be fitted based on a large number of numerical simulation data by considering multi-factor changes. Equation (12) can be written further as:

$$
Y=\frac{\sqrt{K_{1} \operatorname{Ln}\left(X_{1}\right)+K_{2}}}{e^{K_{3} X_{3} X_{4} K_{4} X_{5} K_{5}}}+K_{6} X_{2}+K_{7}
$$

where $K_{1}, K_{2}, K_{3}, K_{4}, K_{5}, K_{6}, K_{7}$ are the undetermined coefficients, which can be obtained by fitting the numerical simulation data, dimensionless.

Combining with the attenuation coefficient model of the downhole perforation pressure in the wellbore of Equation (10), the final prediction model of perforation peak pressure at different positions of the wellbore can be obtained in:

$$
P w=P_{\max }\left(\frac{\sqrt{A L n\left(X_{1}\right)+B}}{e^{0.33 X_{3} X_{4}{ }^{0.02} X_{5}{ }^{0.01}}}+C X_{2}+D\right) e^{0.037 k}
$$

where $A, B, C, D$ are the undetermined coefficients, which can be solved, dimensionless $A=0.13$, $B=0.35, C=0.33, D=0.27$.

Through the above analysis, a calculation model for the prediction of the fluctuating peak pressure of downhole deepwater perforation has been obtained, which can be applied to the field perforation case study.

\section{Field Application}

The field case is a deepwater well located in the South China Sea [51]. The well's depth is $1295 \mathrm{~m}$, the length of the perforating gun, rathole length, and tubing is, respectively, $9 \mathrm{~m}, 19.14 \mathrm{~m}$, $35 \mathrm{~m}$. The packer adopts a static type with rated working pressure of $30 \mathrm{MPa}$. The specific operation parameters of the field well are shown in Table 8 . The measured perforation pressure-time curve can be obtained by the test instrument installed on the perforation gun, as shown in Figure 14 . 
Table 8. Field case parameters.

\begin{tabular}{cc}
\hline Parameters & Data \\
\hline Perforation bullets & 336 \\
Charge per hole & $40 \mathrm{~g}$ \\
Casing size & $244.40 / 220.50 \mathrm{~mm}$ \\
Tubing size & $73.02 / 62.00 \mathrm{~mm}$ \\
Gun size & $177.80 / 152.53 \mathrm{~mm}$ \\
Wellbore initial pressure & $10 \mathrm{MPa}$ \\
Fluid density & $1030 \mathrm{~kg} / \mathrm{m} 3$ \\
Confining pressure & $12 \mathrm{MPa}$ \\
Cement thickness & $0.06 \mathrm{~m}$ \\
Formation elastic modulus & $1.27 \mathrm{MPa}$ \\
Charge type & RDX \\
Perforation type & TCP (Tubing Conveyed Perforation) \\
\hline
\end{tabular}

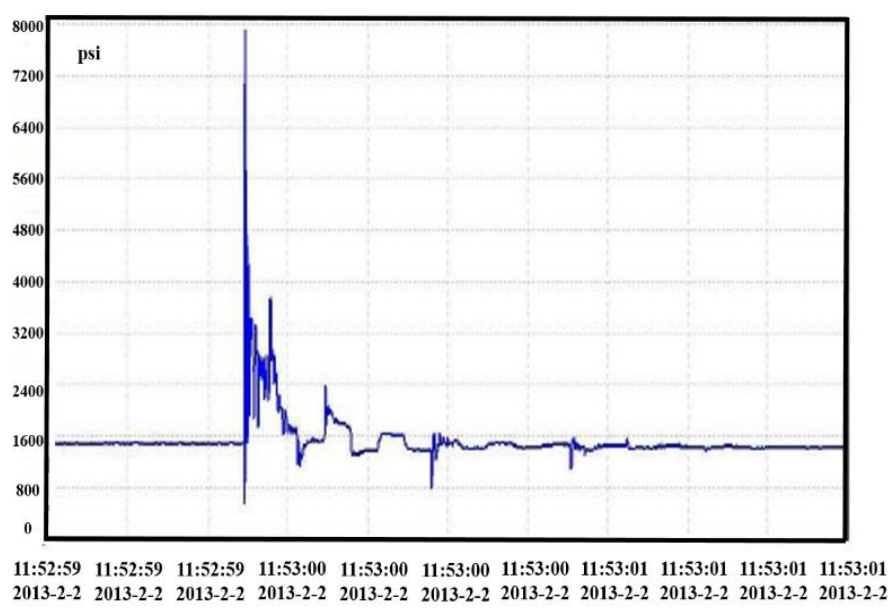

Figure 14. Measured perforation pressure-time curve.

It can be seen that the measured and simulated pressure-time curves of Figures 6 and 14 show similar trends, in which the perforation pressure reaches peak instantaneously with the detonation of the perforating bullets. Then, the oscillation occurs when shock waves are reflected back and forth in the wellbore, and the attenuation occurs due to propagation in the wellbore fluid. Finally, the pressure value tends to be stable after perforation. The measured peak pressure during perforating is $7900 \mathrm{psi}$ (54.57 MPa). According to the prediction model of perforation peak pressure of Equation (13), the result can be obtained. The downhole effective volume for perforation can be calculated in:

$$
V_{0}=V_{t}+V_{g}+V_{r}
$$

where $V_{t}, V_{g}, V_{r}$ are the volume of tubing section, perforating gun section, and pocket section, respectively, $\mathrm{m}^{3}$. The predicted peak perforation pressure by this study (Equation (13)) has been found to be $56.85 \mathrm{MPa}$; the error between the predicted value and the measured value can be calculated by:

$$
\delta=\frac{56.85-54.57}{54.57} \times 100 \%=4.18 \%
$$

Similarly, the results of different empirical formulas (Equations (1)-(4)) in previous reports for calculating the peak pressure of perforation and the errors in comparison with the measured data can be obtained, as shown in Table 9 . 
Table 9. Calculation results of different empirical formulas.

\begin{tabular}{cccc}
\hline Formula Number & $\begin{array}{c}\text { Calculation Result } \\
\text { (MPa) }\end{array}$ & $\begin{array}{c}\text { Measured Result } \\
\text { (MPa) }\end{array}$ & Relative Error \\
\hline Equation (1) & 19.89 & 54.57 & $63.55 \%$ \\
Equation (2) & 39.54 & 54.57 & $27.54 \%$ \\
Equation (3) & 85.68 & 54.57 & $57.01 \%$ \\
Equation (4) & 71.2 & 54.57 & $30.47 \%$ \\
Equation (13) & 56.85 & 54.57 & $4.18 \%$ \\
\hline
\end{tabular}

By comparing the results of this study with those of previous studies, it has been found that the error in comparison with the measured data by Equation (13) is within $10 \%$. The result calculated by the prediction model accords with the accuracy needs of actual perforation operation. The safety of downhole perforation can be analyzed, in which the safety of the packer is an important index to measure the safety of downhole wellbore. When the packer is seated, it is in a fixed state. When the perforation pressure wave is transmitted to the lower end of the packer, it will produce reflection and transmission. According to the principle of reflection and transmission of the wave, the pressure value acting on the packer can be calculated by:

$$
P_{1}=P_{2}+P_{3}-P_{4}=2 P_{2} \times \frac{(\rho c)_{2}\left[(\rho c)_{2}-(\rho c)_{1}\right]}{\left[(\rho c)_{1}+(\rho c)_{2}\right]^{2}}
$$

where $P_{1}$ is the final pressure value acting on the packer, $\mathrm{MPa} ; P_{2}$ is the perforation pressure of the lower end of the packer, $\mathrm{MPa} ; P_{3}$ is the reflection pressure, $\mathrm{MPa} ; P_{4}$ is the transmission pressure, $\mathrm{MPa}$; $\frac{(\rho c)_{1}}{(\rho c)_{2}}=\frac{1}{5}$ is the ratio of shock impedance between wellbore fluid and the packer, dimensionless.

Combining with the prediction model of perforation peak pressure at different positions of the wellbore of Equation (14), the final pressure value acting on packer can be obtained as $51.37 \mathrm{MPa}$. The value is beyond the range of a packer $(30 \mathrm{MPa})$, and the packer will be damaged with such perforating peak pressure. To ensure the safety of perforation while keeping the perforation strength is an important challenge. It means that the number of perforating bullets and charge quantity cannot be reduced. The material properties, type, and size of the downhole string cannot be changed, and the reservoir conditions are determined. The perforating pressure can be reduced by adjusting the installation distance of the packer and the installation of shock absorbers. The shock absorbers are usually installed below the packer to ensure the safety of the whole perforation process. The shock absorber is usually composed of spring or rubber parts. For deepwater wells, the rubber parts in the shock absorber are more easily damaged due to the complex bottom-hole environment, which causes great trouble to perforation operation. So, the spring shock absorber is often used in the perforation of a deepwater well. According to the previous analysis, the axial dynamic response of the downhole string under perforation impact is the most obvious. The perforating peak pressure can be alleviated by installing the longitudinal spring shock absorber. It is proposed that the shock absorbers installed in the middle of the string can achieve the best shock absorption effect [5].

The shock absorber is simulated by adding spring elements connected in series to the string in the numerical model of Figure 3. The numerical models with shock absorbers installed in the middle of the string have been used to carry out the simulation calculation. Through the numerical simulations, the date of perforating peak pressure on the packer with a different number of shock absorbers under different packer setting distances can be obtained, as shown in Figure 15. 


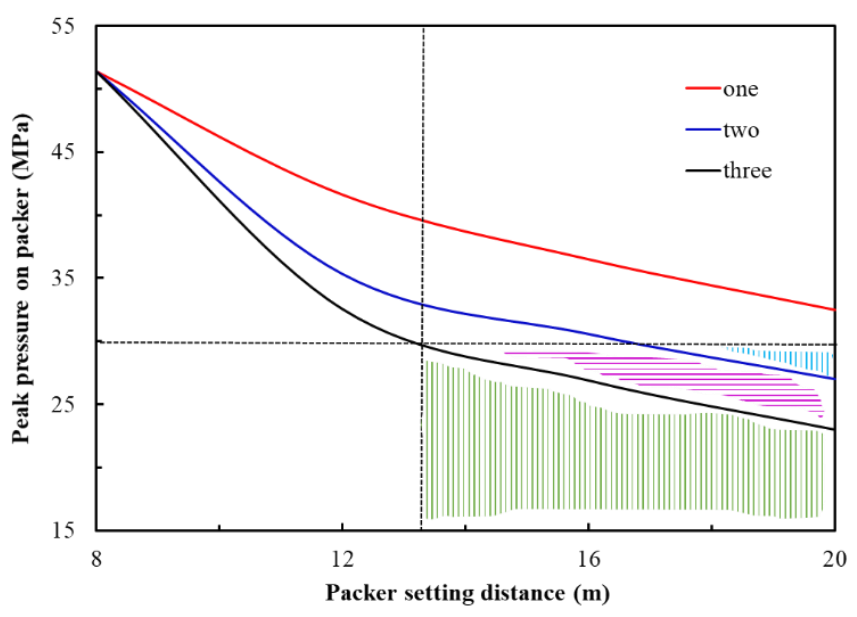

Figure 15. Safety optimization scheme.

Figure 15 shows the reduction of the peak value of perforating pressure on the downhole packer with different numbers of shock absorbers. The more the number of shock absorbers is, the larger the reduction is, and the better shock absorption effect can be achieved. With the increase of packer installation distance, the peak value of the perforating pressure on the downhole packer decreases. When one shock absorber is installed, the minimum value is reduced to $32.5 \mathrm{MPa}$, which still exceeds the range of a packer $(30 \mathrm{MPa})$. When the optimal installation position cannot meet the requirements of shock absorption, the number of shock absorbers can be increased. With the increase of the number of shock absorbers, the downhole packer can be ensured in a safe state combined with the optimization of packer installation distance. The optimization range refers to the color region in Figure 15. Through the above analysis, the specific optimization scheme is put forward. In the field operation, the distance of the packer is $20 \mathrm{~m}$, and two shock absorbers are installed in series in the middle of the string. After safety optimization, there is no damage to the downhole packer after perforation.

\section{Conclusions}

In this paper, the numerical model with hundreds of perforation bullets is set up to study the downhole perforation pressure for deepwater wells. The downhole dynamic perforation process is clearly described. The propagation attenuation model of perforation impact pressure in wellbore fluid is established based on the theory of underwater explosion. According to the results of orthogonal numerical simulation tests, the order of influence of each factor on the peak value of perforation pressure has been obtained: wellbore initial pressure $>$ total charge quantity $>$ thickness of casing and cement $>$ downhole effective volume for perforation $>$ formation elastic modulus. The results show that the downhole perforation peak pressure, logarithmically related to the total charge quantity, is linearly related to the wellbore initial pressure, has an exponential relationship with the downhole effective volume for perforation, and is a power relationship with the casing and cement thickness and the formation elastic modulus. The model to predict the perforation peak pressure considering multiple factors at different positions of the wellbore has been obtained. The proposed correlation shows accurate performance based on a field case under consideration, which demonstrates promising capability as a predictive tool. With the field application, an optimized scheme is proposed to improve the perforation safety for the deepwater well.

Author Contributions: All the authors conceived and designed the study. Investigation, Q.D. and H.Z.; Writing-original draft, Q.D. and H.Z.; Writing-review and editing, J.L., X.H., and B.Z.

Funding: This research received no external funding.

Acknowledgments: The authors gratefully acknowledge the Natural Science Foundation of China (Grant No. U1762211, Grant No. 51734010, Grant No. 51574262, Grant No.51774304, Grant No. 51774063), National Oil and Gas Major Project (Grant No. 2017ZX05009), the Foundation for Innovative Research Groups of the National 
Natural Science Foundation of China (Grant No. 51521063), the State Key Laboratory of Petroleum Resources and Engineering.

Conflicts of Interest: The authors declare that there is no conflict of interest regarding the publication of this paper.

\section{References}

1. Brockway, P.E.; Owen, A.; Brand-Correa, L.I.; Hardt, L. Estimation of Global Final Stage Energy Return-On-Investment for Fossil Fuels with Comparison to Renewable Energy Sources. Nat. Energy 2019, 4, 612-621. [CrossRef]

2. Xi, Y.; Li, J.; Liu, G.; Li, J.; Jiang, J. Mechanisms and Influence of Casing Shear Deformation near the Casing Shoe, Based on MFC Surveys during Multistage Fracturing in Shale Gas Wells in Canada. Energies 2019, 12, 372. [CrossRef]

3. Gilliat, J.; Bale, D.; Satti, R.P.; Li, C.; Howard, J.J. The Importance of Pre-Job Shock Modeling as a Risk Mitigation Tool in TCP Operations. In Proceedings of the SPE Deepwater Drilling and Completions Conference, Galveston, TX, USA, 10-11 September 2014.

4. McLeod, H.O., Jr. The Effect of Perforating Conditions on Well Performance. J. Pet. Technol. 1983, 35, 31-39. [CrossRef]

5. Giunta, R.; Le, C.; Schoener-Scott, M.; Anderson, R.; Glass, J. Modeling Dynamic Shock Loads for High-Pressure/Deep-Water Tubing-Conveyed Perforating Operations in the Gulf of Mexico. In Proceedings of the SPE Deepwater Drilling and Completions Conference, Galveston, TX, USA, 20-21 June 2012.

6. Deng, Q.; Zhang, H.; Li, J.; Hou, X.; Wang, H. Study of Downhole Shock Loads for Ultra-Deep Well Perforation and Optimization Measures. Energies 2019, 12, 2743. [CrossRef]

7. Qiu, Q.; Cui, L. Reliability Evaluation Based on a Dependent Two-stage Failure Process with Competing Failures. Appl. Math. Model. 2018, 64, 699-712. [CrossRef]

8. Qiu, Q.; Cui, L. Optimal Mission Abort Policy for Systems Subject to Random Shocks Based on Virtual Age Process. Reliabil. Eng. Syst. Saf. 2019, 189, 11-20. [CrossRef]

9. Lu, D.T.; Xu, G.M.; Kong, X.Y. Calculating Transient Pressure of Wellbore Taking under Perforation Condition with Parallel Computation Method. Univ. Sci. Technol. China 1999, 29, 638-643.

10. Zhao, X.; Liu, G.H. Theoretical Modeling of the Movement of the Top Killing Fluids in Complex Perforation. Drill. Fluid Complet. Fluid 2008, 25, 7-9.

11. Zhao, X.; Liu, G.H.; Li, J. Experimental Study of the Movement of Control Fluid in Compound Perforation. Pet. Sci. 2009, 6, 389-394. [CrossRef]

12. Chen, H.B.; Tang, K.; Ren, G.H. String Dynamic Mechanics Analysis on Ultra-Deep Perforation. Well. Logging Technol. 2010, 34, 487-491.

13. Sanders, W.; Baumann, C.E.; Williams, H.A.R.; de Moraes, F.D.; Shipley, J.; Bethke, M.E.; Ogier, S. Efficient Perforation of High-Pressure Deepwater Wells. In Proceedings of the Offshore Technology Conference, Houston, TX, USA, 2-5 May 2011.

14. Yang, X.T.; Zhang, F.X.; Li, M.F.; Dou, Y.H. Analysis of strength safety of perforated string considering detonation parameters. Adv. Mater. Res. 2013, 634, 3573-3576. [CrossRef]

15. Zhou, H.F.; Ma, F.; Chen, H.B.; Xu, Y.X.; Xi, L.X.; W, S.S. Comprehensive dynamic load test for the column in perforation section. Well Logging Technol. 2014, 38, 247-250.

16. Bale, D.; Satti, R.; Ji, M. A Next-generation Shock-capturing, Multi-phase Flow Simulator for Perforating Applications in HPHT Environment. In Proceedings of the SPE Deepwater Drilling \& Completions Conference, Galveston, TX, USA, 14-15 September 2016.

17. Li, Z.F.; Zhang, C.Y.; Song, G.M. Research Advances and Debates on Tubular Mechanics in Oil and Gas Wells. J. Pet. Sci. Eng. 2017, 151, 194-212. [CrossRef]

18. Liu, J.; Guo, X.Q.; Liu, Z.J.; Liu, X.; Liu, Q.Y. Pressure Field Investigation into Oil \& Gas Wellbore during Perforating Shaped Charge Explosion. J. Pet. Sci. Eng. 2019, 172, 1235-1247.

19. Lu, D.W. Perforating Technology for Oil and Gas Wells; Petroleum Industry Press: Beijing, China, 2012.

20. Chen, F.; Chen, H.B.; Tang, K. Influence of Perforating Impact Load on the Operating String and the Countermeasures. Nat. Gas Ind. 2010, 30, 61-65.

21. Ning, J.G.; Wang, C.; Ma, T.B. Explosion and Shock Dynamics; National Defense Industry Press: Beijing, China, 2010. 
22. Kamlet, M.J.; Jacobs, S.J. Chemistry of Detonations. I. A Simple Method for Calculating Detonation Properties of C-H-N-O Explosives. J. Chem. Phys. 1968, 48, 23-35. [CrossRef]

23. Deng, Q.; Zhang, H.; Li, J.; Hou, X.; Wang, H. Analysis of Impact Load on Tubing and Shock Absorption during Perforating. Open Phys. 2019, 17, 214-221. [CrossRef]

24. Gao, Y.D.; Wang, S.H.; Wang, X.C.; Liu, Z.Y.; Guo, S.S.; Tang, J.J. Assessment Packer in Perforating String in Safety Distance. Well Logging Technol. 2016, 40, 382-384.

25. Baumann, C.E.; Pesantes, E.; Guerra, J.; William, A.; Williams, H. Reduction of Perforating Gunshock Loads. SPE Drill. Complet. 2012, 27, 65-74. [CrossRef]

26. Baumann, C.E.; Oden, J.T. An Adaptive-Order Discontinuous Galerkin Method for the Solution of the Euler Equations of Gas Dynamics. Int. J. Numer. Methods Eng. 2002, 47, 61-73. [CrossRef]

27. Bale, D.; Ji, M.; Satti, R.; Gilliat, J. Advances in Numerical Modeling of Downhole Dynamics for Perforated Well Completions. In Proceedings of the SPE Annual Caspian Technical Conference and Exhibition, Astana, Kazakhstan, 12-14 November 2013. SPE-172308-MS. [CrossRef]

28. Lee, W.H. Oil Well Perforator Design Using 2D Eulerian Code. Int. J. Impact Eng. 2002, 27, 535-559. [CrossRef]

29. Han, X.Q.; Cao, L.N.; Cao, Y.X.; Zhang, Y.G. Numerical Simulation of the Shaped Charge Jet Formation and Penetration through the Wall of Perforating Gun. Eng. Sci. Technol. 2009, 9, 6960-6964.

30. Kang, K.; Ma, F.; Zhou, H.F. Study on Dynamic Numerical Simulation of String Damage Rules in Oil-gas Well Perforating Job. Procedia Eng. 2014, 84, 898-905.

31. Yang, Z.Z. Dynamic Response of String under Perforating Pulse Load. Master's Thesis, China University of Petroleum (East China), Qingdao, China, 2015.

32. Li, B.Y. Analysis of Strength and Safety of Packer Central Tube under Perforating Impact Loading. Master's Thesis, Xi'an Shiyou University, Xi'an, China, 2018.

33. Yan, Y.; Guan, Z.; Xu, Y.; Yan, W.; Wang, H. Numerical Investigation of Perforation to Cementing Interface Damage Area. J. Pet. Sci. Eng. 2019, 179, 257-265. [CrossRef]

34. Mirzaei, M.; Harandi, A.; Karimi, R. Finite Element Analysis of Deformation and Fracture of an Exploded Gas Cylinder. Eng. Fail. Anal. 2009, 16, 1607-1615. [CrossRef]

35. Villavicencio, R.; Soares, C.G. Numerical Modelling of the Boundary Conditions on Beams Stuck Transversely by a Mass. Int. J. Impact Eng. 2011, 38, 384-396. [CrossRef]

36. Ma, S.; Zhang, X.; Qiu, X.M. Comparison Study of MPM and SPH in Modeling Hyper-Velocity Impact Problems. Int. J. Impact Eng. 2009, 36, 272-282. [CrossRef]

37. Elshenawy, T.; Elbeih, A.; Li, Q. Influence of Target Strength on the Penetration Depth of Shaped Charge Jets into RHA Targets. Int. J. Mech. Sci. 2018, 136, 234-242. [CrossRef]

38. Chen, C.Y.; Shiuan, J.H.; Lan, I.F. The Equation of State of Detonation Products Obtained from Cylinder Expansion test. Propellants Explos. Pyrotech. 1994, 19, 9-14. [CrossRef]

39. Elshenawy, T.; Li, Q. Influences of Target Strength and Confinement on the Penetration Depth of an Oil Well Perforator. Int. J. Impact. Eng. 2013, 54, 130-137. [CrossRef]

40. LS-DYNA. Keyword User's Manual; Version 971; Livermore Software Technology: Livermore, CA, USA, 2013.

41. Wei, Q.; Jones, N. A Failure Criterion for Beams under Impulsive Loading. Int. J. Impact Eng. 1992, 12, 101-121.

42. API. Technical Report on Equations and Calculations for Casing, Tubing and Line Pipe Used as Casing or Tubing; and Performance Properties Tables for Casing and Tubing, TR 5C3; API: Washington, DC, USA, 2008.

43. Yu, Y.; R, F.Y. Application of Packer in Fracture Perforating. J. Xi'an Univ. Sci. Technol. 2007, 27, $423-425$.

44. Deng, Q.; Zhang, H.; Li, J.; Hou, X.; Wang, H. Safety Distances of Packers for Deep-water Tubing-conveyed Perforating. In Proceedings of the Offshore Technology Conference, Houston, TX, USA, 5-7 November 2018.

45. Cheraghian, G.; Hemmati, M.; Bazgir, S. Application of $\mathrm{TiO}_{2}$ and Fumed Silica Nanoparticles and Improve the Performance of Drilling Fluids. AIP Conf. Proc. 2014, 1590, 266-270.

46. Cheraghian, G. Application of Nano-Particles of Clay to Improve Drilling Fluid. Int. J. Nanosci. Nanotechnol. 2017, 13, 177-186.

47. Deng, Q.; Zhang, H.; Li, J.; Wang, H.; Cai, Z.Y.; Tan, T.Y.; Hou, X.J. A Model for Estimating Penetration Length under Different Conditions. In Proceedings of the 52nd US Rock Mechanics/Geomechanics Symposium, Seattle, WA, USA, 17-20 June 2018; Available online: https://www.onepetro.org/conference-paper/ARMA2018-344 (accessed on 1 June 2019). 
48. Sun, T.; Zhang, H.; Gao, D.; Liu, S.; Cao, Y. Application of the Artificial Fish Swarm Algorithm to Well Trajectory Optimization. Chem. Technol. Fuels Oils 2019, 55, 213-218. [CrossRef]

49. Cheraghian, G.; Wu, Q.; Mostofi, M.; Li, M.C.; Afrand, M.; Sangwai, J.S. Effect of a Novel Clay/Silica Nanocomposite on Water-Based Drilling Fluids: Improvements in Rheological and Filtration Properties. Colloid Surf. A 2018, 555, 339-350. [CrossRef]

50. A Cole, R.H. Underwater Explosion; LISA Princeton University Press: Princeton, NJ, USA, 1948.

51. Teng, Y.S. Dynamic Simulation for Perforating and String Safety Evaluation. Master's Thesis, China University of Petroleum (East China), Beijing, China, 2014.

(C) 2019 by the authors. Licensee MDPI, Basel, Switzerland. This article is an open access article distributed under the terms and conditions of the Creative Commons Attribution (CC BY) license (http://creativecommons.org/licenses/by/4.0/). 